\title{
Role of Krebs Cycle in the Mechanism of Stability Internal Medium and Internal Energy in an Organism in Norm and in Mechanisms of Cancer Pathology
}

\section{Ponizovskiy MR}

Kiev Regional, Head of Laboratory Biochemistry and Toxicology, PN Hospital, Nuernberg, Germany

\begin{abstract}
The mechanisms stability of both an open non equilibrium non linear thermodynamic system of a human organism and the open non equilibrium non linear thermodynamic system of an organism's cells were considered via study the mechanism operation of Krebs tricarboxylic acid or citric acid cycle. Just study mechanism operation of Krebs tricarboxylic acid cycle in open thermodynamic systems of both an organism and an organism's cells gives possibility to describe the biochemical and biophysical mechanisms interactions between anabolic processes and catabolic processes considering mutual influences between anaerobic catabolic processes and aerobic catabolic processes. Also there was explained the role of Krebs cycle in biochemical and biophysical mechanisms of stability open non equilibrium nonlinear thermodynamic system of a human organism and an organism's cells. Besides there were described the influences of Krebs cycle property on mechanisms operation of cellular capacitors contributing to maintenance stability Internal Energy both an organism and cells of an organism due to remote cellular reactions via cellular capacitors operations preceding contacts cellular reactions which leads to immune reaction on strange objects into an organism saving stability Internal Energy and Internal Medium as an organism as well as cells of an organism. Moreover there were described the mechanism of partial destruction Krebs acids cycles leading to partial violation of interactions between catabolic anaerobic processes and catabolic aerobic processes due to partial inhibition catabolic processes in Warburg effect mechanism of cancer metabolism. Also there was described the mechanisms of the offered method prevention supplementary metastasis in processes of up-to-date chemotherapy and was described practical application of this method treatment on the cancer disease patient.
\end{abstract}

Keywords: Glycolysis; Krebs tricarboxylic citric acid cycle; Anabolic endergonic processes; Catabolic aerobic exergonic processes; Catabolic anaerobic exergonic processes; Cellular capacitors; Cellular remote reactions

\section{Introduction}

The stability of both an open non equilibrium nonlinear thermodynamic system of a human organism and the open non equilibrium nonlinear thermodynamic system of an organism's cells display balance catabolic exergonic processes and anabolic endergonic processes [1,2]. Catabolic anaerobic oxidative phosphorylation of glycolysis exerts the driving mechanism as anabolic endergonic processes as well as catabolic anaerobic exergonic processes via sharing these reverse processes in "nodal point of bifurcation anabolic and catabolic processes [NPBac]" of Acetyl-CoA [3,4] (Figure 1). TCA prolong catabolic anaerobic exergonic processes of glycolysis oxidative phosphorylation after "nodal point of bifurcation anabolic and catabolic processes [NPBac]" creating link between anaerobic catabolic exergonic processes and aerobic catabolic exergonic processes in mitochondria of cells which interact with catabolic system of Hemoglobin's in erythrocytes of an organism's blood. On the one hand, TCA is the link between catabolic anaerobic exergonic processes and catabolic aerobic exergonic oxidative processes. On the other hand, catabolic processes of TCA are contrary anabolic endergonic processes. Besides the influences of Krebs cycle property on mechanisms operation of cellular capacitors contribute to maintenance stability Internal Energy both an organism and cells of an organism due to remote cellular reactions via cellular capacitors operations preceding contacts cellular reactions which leads to immune reaction on strange objects into an organism saving stability Internal Energy and Internal Medium as an organism as well as cells of an organism. Just all these functions of TCA contribute to as mechanisms stability Internal Energy and Internal Medium both an organism's cells and an organism as well as all cellular capacitors operation causing defense of Internal Energy and Internal Medium of an organism leading to stable Stationary State of an organism. Also it occurs partial destruction Krebs acids cycles leading to partial violation of interactions between catabolic anaerobic processes and catabolic aerobic processes due to partial inhibition catabolic processes in Warburg effect mechanism of cancer metabolism that cause pathologic Quasi-stationary State of an organism. Moreover there was described the mechanisms of the offered method prevention supplementary metastasis in processes of up-to-date chemotherapy and was described practical application of this method treatment on the cancer disease patient.

Krebs tricarboxylic acids cycle as the link of the mechanism maintenance stability internal energy in an organism

The ATP is produced in mitochondria via the process of oxidative phosphorylation. It occurs in such pathway: Electrons are transferred through the reducing substances of nicotinamide adenine dinucleotide $(\mathrm{NADH})$ to Complex I (NADH dehydrogenase) and flavine adenine dinucleotide $\left(\mathrm{FADH}_{2}\right)$ to Complex II and further through Complex III (cytochrome bc complex) then Complex IV (cytochrome $c$ oxidase) to Complex V (ATP synthase) [5,6]. AKT is the primer for both catabolic processes and anabolic processes because AKT exerts Glycolysis advancing both catabolic exergonic and anabolic endergonic processes through "nodal point of bifurcation anabolic and catabolic processes

*Corresponding author: Ponizovskiy MR, Head of Laboratory Biochemistry and Toxicology, PN Hospital, Herschelstrasse 33, 90443 Nuernberg, Germany, Tel: 499116537811; E-mail: ponis@online.de

Received October 06, 2016; Accepted October 21, 2016; Published October 31 2016

Citation: Ponizovskiy MR (2016) Role of Krebs Cycle in the Mechanism of Stability Internal Medium and Internal Energy in an Organism in Norm and in Mechanisms of Cancer Pathology. Mod Chem Appl 4: 191. doi: 10.4172/2329-6798.1000191

Copyright: (c) 2016 Ponizovskiy MR. This is an open-access article distributed under the terms of the Creative Commons Attribution License, which permits unrestricted use, distribution, and reproduction in any medium, provided the original author and source are credited. 
Citation: Ponizovskiy MR (2016) Role of Krebs Cycle in the Mechanism of Stability Internal Medium and Internal Energy in an Organism in Norm and in Mechanisms of Cancer Pathology. Mod Chem Appl 4: 191. doi: 10.4172/2329-6798.1000191

Page 2 of 8

[NPBac] of Acetyl-CoA" [3,4,6] (Figure 1). Krebs tricarboxylic acid cycle is the crucial link of both catabolic anaerobic exergonic processes and catabolic aerobic exergonic processes which mechanisms depend on circular characteristic of TCA cycle pathway [3,7,8] (Figure 2). Besides the common pathway of both Glycolysis and TCA cycle gives possibility to combine as both catabolic exergonic anaerobic and aerobic processes as well as opposed them anabolic endergonic processes reflecting balance catabolic exergonic processes and anabolic endergonic processes which is the main link of mechanism maintenance stability Internal Energy of an organism and cells of an organism according first law of thermodynamics $[1,2,9,10]$. First, the final products of Krebs tricarboxylic acid cycle are Carbon dioxide $\left(\mathrm{CO}_{2}\right)$ and Hydrogen ion $\left(\mathrm{H}^{+}\right)$which is transformed into water $\left(\mathrm{H}_{2} \mathrm{O}\right)$ via activity of cellular mitochondria. However, carbon dioxide $\left(\mathrm{CO}_{2}\right)$ cannot be in gaseous state in mitochondria, in cytoplasm, in blood of an organism, but it can be realized only in lung's alveoli of an organism. Thus, carbon dioxide is found in dissolved state as ions of carbon dioxide ( $\left.\mathrm{COO}^{-}\right)$in mitochondria, in cytoplasm and in blood of an organism creating carboxyhemoglobin which carries the ions carbon dioxide $\left(\mathrm{COO}^{-}\right)$to lung's alveolus and then release carbon dioxide $\left(\mathrm{CO}_{2} \uparrow\right.$ ) into atmosphere [11] (Figure 3).

\section{$\mathrm{Hb}^{+}+\mathrm{COO}^{-}=\mathrm{Hb}-\mathrm{OOC} ; \mathrm{Hb}-\mathrm{OOC}=\mathrm{Hb}+\mathrm{CO}_{2} \uparrow$}

Secondly, being the crucial link of both catabolic anaerobic exergonic processes and catabolic aerobic exergonic processes, TCA cycles are found in mitochondria, in cytoplasm and in blood of an organism that should only been considered how the related systems which connect one with others forming common stable catabolic mechanism of anaerobic oxidative phosphorylation. Just this common stable catabolic exergonic mechanism of anaerobic oxidation of Krebs tricarboxylic acids cycles induces stable catabolic exergonic oxidative processes promoting maintenance balance catabolic anaerobic processes and catabolic aerobic processes as the stable link of mechanism stability Internal Energy of open thermodynamic system of an organism according first law of thermodynamics. Thus these connections between Krebs tricarboxylic acids cycles in mitochondria, in cytoplasm and in blood of an organism are realized owing to fulfilling circular metabolic pathway of TCA cycles via transmitting Krebs cycle's crucial product Oxaloacetates from mitochondria into Krebs

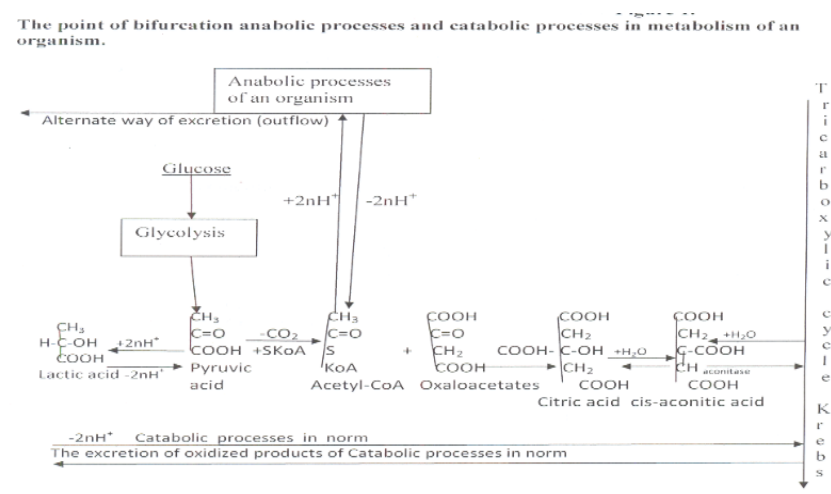

a) Nodal point of bifurcation anabolic and catabolic processes in "Nodal point of bifurcation anabolic and catabolic processes" [NPBac].

b) Moderate metabolic processes displaying balance anabolic and catabolic processes in able-bodied tissue.

c) Accumulation of energy into lactic acid for anabolic processes.

d) Normal excretion substances via catabolic oxidative processes in ablebodied tissue.

Figure 1: The point of bifurcation anabolic and catabolic processes in metabolism of an organism.

\section{Krebs tricarboxvlic acids cycle (TCA) in catabolic exoergonic process.}
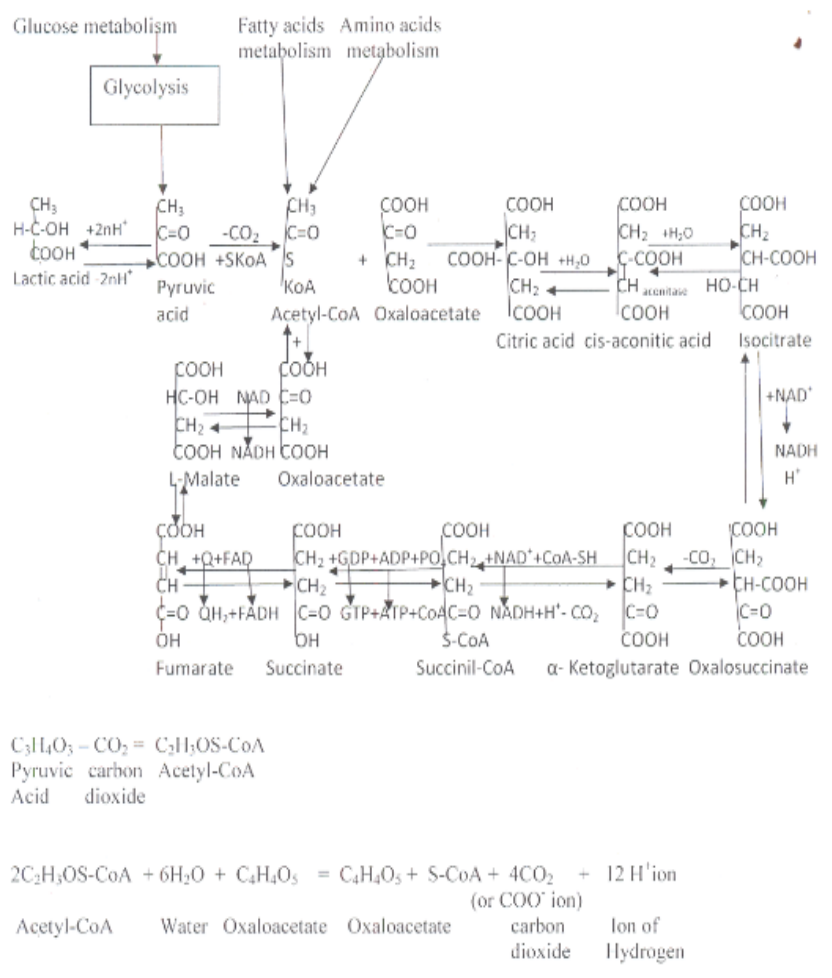

$12 \mathrm{H}^{+}+6 \mathrm{O}=6 \mathrm{H}_{2} \mathrm{O}$

a) Transition catabolic anaerobic processes of oxidative phosphorilation from Glycolysis to Krebs tricarboxilic citric acids (TCA) cycle.

b) Glycolysis' Product "Acetyl-CoA" is as "the nodal point of bifurcation anabolic and catabolic processes [NPBac]" as well as "the one part of the link joining Glycolysis with Krebs tricarboxilic citric acids (TCA) cycle".

c) Oxaloacetate is as the closing link of circular Krebs tricarboxilic citric acids (TCA) cycle as well as "the second part of the link joining Glycolysis with Krebs tricarboxilic citric acids (TCA) cycle".

d) The joint between Acetyl-CoA and Oxaloacetate produces Citric acid as the primary link of driving mechanism Krebs tricarboxilic citric (TCA) cycle which governs direction reaction among Glycolysis and Krebs tricarboxilic citric (TCA) cycle.

e) The final Catabolic Products of Krebs tricarboxilic citric (TCA) cycle are Carbon dioxide and Hydrogen ion.

f) Hydrogen ion is oxidized by Oxygen resulting in Water.

Figure 2: Krebs tricarboxylic acids cycle (TCA) in catabolic exergonic process

tricarboxylic acid cycle of cytoplasm, further produced by Krebs cycle's crucial product Oxaloacetates transmitting from cytoplasm into blood of an organism, and then crucial products of Oxaloacetates, produced by Krebs cycle, returns to mitochondrial Krebs tricarboxylic acids cycles (Figure 3). Circular metabolic pathway of TCA cycles across cells and an organism unites catabolic exergonic anaerobic processes with aerobic oxygen oxidative processes realizing such oxidative processes:

The oxygen is consumed in the capillaries of lung's alveoli and is reacted with hemoglobin of blood's erythrocytes forming Oxyhaemoglobin [11].

a) $\mathrm{Hb}-\mathrm{Fe}^{2+}+\mathrm{O}_{2} \rightarrow\left[\mathrm{Hb}-\mathrm{Fe}^{3+} 2 \mathrm{O}\right]$

An organism's cells accept Oxygen from Oxyhaemoglobin of erythrocytes transforming iron of their heame from $\mathrm{Fe}^{3+}$ into $\mathrm{Fe}^{2+}$ plus free oxygen, i.e., forming Haemoglobin with also releasing free oxygen. 
Free oxygen adds electron, which is produced by serial transformings $\mathrm{NAD}^{+} \leftrightarrow \mathrm{NADH}$ and $\mathrm{FAD} \leftrightarrow \mathrm{FADH}_{2}$, and forms ROS producing moderate quantity dissolved Superoxide:

$$
\text { b) }\left[\mathrm{Hb}^{-\mathrm{Fe}^{3+}} 2 \mathrm{O}\right] \rightarrow \mathrm{Hb}-\mathrm{Fe}^{2+}+\mathrm{O}_{2} \text {; c) } \mathrm{O}_{2}+\mathrm{e}^{-} \rightarrow \mathrm{O}_{2}^{*}
$$

The dissolved Superoxide is transported by electron transport system (ETS) across cellular membranes and mitochondrial membranes binding with cytochrome $\mathrm{c}$ that transforms iron of cytochrome $\mathrm{c}$ from $\mathrm{Fe}^{2+}$ into $\mathrm{Fe}^{3+}$ and form oxidized cytochrome c. Then the oxidized cytochrome $\mathrm{c}$ adds electron and release free Cytochrome $\mathrm{C}$ with free Oxygen. Oxygen reacts with Hydrogen ion from Krebs cycle producing Water due to operation of cytochrome $c$ oxidase, i.e., elimination of free oxygen (Figures 2 and 3 )

d) cytc- $\mathrm{Fe}^{2+}+\mathrm{O}_{2}{ }^{*} \rightarrow\left[\right.$ cytc- $\left.\mathrm{Fe}^{3+} 2 \mathrm{O}^{-}\right]$; e) $\left[\right.$cytc- $\left.\mathrm{Fe}^{3+} 2 \mathrm{O}^{-}\right]+\mathrm{e}^{-} \rightarrow$ cytc$\mathrm{Fe}^{2+}+\mathrm{O}_{2}$

$$
\text { f) cytc- } \mathrm{Fe}^{3+}+\mathrm{O}_{2}{ }^{*} \rightarrow \text { cytc- } \mathrm{Fe}^{2+}+\mathrm{O}_{2} \text { g) } 4 \mathrm{H}^{+}+\mathrm{O}_{2}=2 \mathrm{H}_{2} \mathrm{O}
$$

However, the quantity of consumed oxygen in the capillaries of lung's alveoli are considerably more then the produced Hydrogen ion in Krebs cycle [5,6]. Therefore, there are formed considerably more quantity of surplus Superoxide $\left(\mathrm{O}_{2}^{*}\right)$ from surplus oxygen $\left(\mathrm{O}_{2}\right)$ via adding electron:

\section{h) $\mathrm{n}\left[\mathrm{O}_{2}\right]+\mathrm{n}\left[\mathrm{e}^{-}\right] \rightarrow \mathrm{n}\left[\mathrm{O}_{2}^{*}\right]$}

Then surplus Superoxide $\left(\mathrm{O}_{2}^{*}\right)$ is transported by electron transport system (ETS) into mitochondria. Further surplus Ssuperoxide $\left(\mathrm{O}_{2}^{*}\right)$ reduces Ferric iron $\left[\mathrm{Fe}^{3+}\right]$ into Ferrous iron $\left[\mathrm{Fe}^{2+}\right]$ with oxygen:

$$
\text { i) } \mathrm{O}_{2}{ }^{*}+\text { cytc- } \mathrm{Fe}^{3+} \rightarrow \text { cytc- } \mathrm{Fe}^{2+}+\mathrm{O}_{2} \text {. }
$$

Simultaneously Reactive Oxygen Species (ROS) is generated by NOX (NADPH oxidase) and Duoxs due to activity mitochondrial aerobic catabolic processes forming of this surplus quantity of mitochondrial Superoxide $\left(\mathrm{O}_{2}^{*}\right)$ which don't continue processes of anaerobic oxidative phosphorylation and don't lead down to final products $\mathrm{CO}_{2}$ and $\mathrm{H}_{2} \mathrm{O}$. Just $\mathrm{NAD}^{+}$and $\mathrm{FAD}$ are transformed: $\mathrm{NAD}^{+}$is transformed into reduced molecule NADH due to NADPH dehydrogenase operation, and $\mathrm{FAD}$ is transformed into reduced molecule $\mathrm{FADH}_{2}$. Then $\mathrm{NADH}$ is back oxidized into $\mathrm{NAD}^{+}$by NADH oxidase operation at Complex I, and pair of electrons from $\mathrm{NADH}$ is released passing via series of electron transport carriers of electron transport system (ETS) to coenzyme Q into complex II and further through Complex III (cytochrome bc complex) then Complex IV (cytochrome c oxidase) to Complex V (ATP synthase) into the intermembrane space $[5,6]$.

The partial supplementary Superoxide anion $\left[\mathrm{O}_{2}^{*}\right]$ is accumulated into forming Reactive Oxygen Species [ROS], and the rest supplementary Superoxide anion $\left[\mathrm{O}_{2}^{*}\right]$ reacts with hydrogen cations forming hydrogen peroxide and oxygen:

$$
\text { j) } 2 \mathrm{O}_{2}^{*_{-}}+2 \mathrm{H}^{+}=\mathrm{H}_{2} \mathrm{O}_{2}+\mathrm{O}_{2}
$$

Further there is happened Haber -Weiss reaction of iron catalysed by superoxide transformations being passed into Fenton reaction which is applied to mitochondria producing free radicals $\left[{ }^{*} \mathrm{OH}\right]$ in such mode $[5,6]$ :

$$
\begin{aligned}
& \text { k) cytc- } \mathrm{Fe}^{2+}+\mathrm{H}_{2} \mathrm{O}_{2} \rightarrow \text { cytc- } \mathrm{Fe}^{3+}+{ }^{-} \mathrm{OH}+{ }^{*} \mathrm{OH} \\
& \text { cytc- }-\mathrm{Fe}^{3+}+\mathrm{O}_{2}{ }^{*} \rightarrow \text { cytc- } \mathrm{Fe}^{2+}+\mathrm{O}_{2} \\
& \mathrm{O}_{2}{ }^{*}+\mathrm{H}_{2} \mathrm{O}_{2} \rightarrow{ }^{-} \mathrm{OH}+{ }^{*} \mathrm{OH}+\mathrm{O}_{2}+\mathrm{Fe}^{3+}
\end{aligned}
$$

Thus these converting's of supplementary respired oxygen lead to creation complex $\mathrm{ROS} / \mathrm{H}_{2} \mathrm{O}_{2}$ /free radicals $\left({ }^{*} \mathrm{OH}\right)$ which pass through mitochondrial membranes, through cytoplasm and nuclear membranes penetrating into nucleus to nuclear DNA. On the one hand, ROS is neutralized by glutathione peroxidise (GPX) and phospholipid hydroperoxide glutathione peroxidise (PHGPX) in normal G1/S phases of cellular cycle $[5,6]$. On the other hand, moderate anabolic processes transit into intensive anabolic processes in nucleus, and simultaneously moderate catabolic processes transits into intensive catabolic processes in mitochondria mechanism maintenance stability chemical potential of cytoplasm $\left(\mu_{\text {cytopl }}\right)$ via maintaining balance catabolic processes and anabolic processes in cytoplasm that leads to production surplus complex ROS $/ \mathrm{H}_{2} \mathrm{O}_{2}$ in normal $\mathrm{G}_{2}$ phase of cellular cycle [6]. Complex $\mathrm{ROS} / \mathrm{H}_{2} \mathrm{O}_{2}$ generates superoxide $\left[\mathrm{O}_{2}^{*}\right]$ into nucleus which induces free radicals $\left({ }^{*} \mathrm{OH}\right)$. Free radicals $\left({ }^{*} \mathrm{OH}\right)$ react with nuclear DNA (nDNA) and induce process replication via realizing of 2nDNA [6-13].

$$
\text { 1) }{ }^{*} \mathrm{OH}+\mathrm{H}_{2} \text {-nDNA-DNA --> } \mathrm{H}_{2} \mathrm{O}+\mathrm{H}^{\bullet} \text {-nDNA-DNA }
$$

$$
\mathrm{O}^{*}+2 \mathrm{H}_{2} \mathrm{O}-\rightarrow 2 \mathrm{H}^{\bullet}+2 \mathrm{OH}^{-}
$$

$2 \mathrm{H}^{\bullet}-\mathrm{nDNA}-\mathrm{DNA}+2 \mathrm{H}^{\bullet}-->2 \mathrm{nDNA}-\mathrm{H}^{\bullet}+2 \mathrm{nDNA}-\mathrm{H}^{\bullet}$

$$
2 \mathrm{nDNA}-\mathrm{H}^{\bullet}+2^{*} \mathrm{OH}-->2 \mathrm{nDNA}+\mathrm{H}_{2} \mathrm{O}
$$

Thus the free radicals ( ${ }^{*} \mathrm{OH}$ and $\mathrm{H}^{*}$ ) are neutralized in final $\mathrm{G}_{2}$ phase of DNA replication. Then it occurs $\mathrm{M}$ phase of cellular cycle of Mitosis in cell division that transfers the new cells into $G_{0}$ phase of normal cellular cycle. Thus, nuclei DNA (nDNA) of formed new cells are not subjected to ruining capability of ROS $/ \mathrm{H}_{2} \mathrm{O}_{2}$ /free radicals in normal development cellular cycle $[2,5,6]$. Such mutual influences between nucleus and mitochondria induce chemical potentials of cellular cytoplasm's in $G_{0}$, $G_{1} / S, G_{2}$ and $M / G_{0}$ phases normal cellular cycle which are related to chemical potentials an organism maintaining stable Internal Energy and Internal Medium both in an organism and cells of an organism via cellular capacitors, nuclear capacitors and mitochondrial capacitors operations in common interconnection and mutual interdependence [2,4-6]. Just these related chemical potentials are supported by the operations of nuclear capacitors, mitochondrial capacitors and cellular capacitors via generating relative resonance waves between cells and an organism in norm [4-6,12]. Just Krebs tricarboxylic acids cycle carries out the role of main driving mechanism of production supplementary superoxide $\left(\mathrm{O}_{2}^{*}\right)$ : a) The quantity Hydrogen ion $\left(\mathrm{H}^{+}\right)$, produced in TCA, reacts with free Oxygen $\left(\mathrm{O}_{2}\right)$ and forms Water $\left(\mathrm{H}_{2} \mathrm{O}\right)$ that eliminates free Oxygen in liquids of an organism and cells. b) The supplementary oxygen $\left(\mathrm{O}_{2}\right)$, which did not react with Hydrogen ion $\left(\mathrm{H}^{+}\right)$produces supplementary superoxide $\left(\mathrm{O}_{2}{ }^{*}\right)$ which generates free radicals exerting replications in $\mathrm{G}_{2}$ phase of cellular cycle [6]. Thus, on the one hand, TCA influences on anabolic processes due to production supplementary superoxide $\left(\mathrm{O}_{2}^{*}\right)$ and generating Free radicals $\left({ }^{*} \mathrm{OH}\right)$ which induce nuclear proliferative processes in $\mathrm{G}_{2}$ phase of cellular cycle [2-6]. On the other hand, the pathway of Glycolysis is divided in "nodal point of bifurcation of anabolic and catabolic processes" [NPBac] of Acetyl-CoA, in which it occurs mutual influences between anabolic endergonic processes and catabolic exergonic processes [3,4] (Figure 1). Just Krebs tricarboxylic citric acid cycle, joining catabolic anaerobic and aerobic processes, is the link which influences on maintenance stability of balance catabolic exergonic processes and anabolic endergonic processes through its main crucial point of molecules citric acids and "nodal point of bifurcation of anabolic and catabolic processes [NPBac] in Acetyl-CoA". Thus it occurs mutual influences between anabolic endergonic processes and Krebs tricarboxylic acid (TCA) cycle through crucial molecules of Acetyl-CoA and Citric Acids for maintenance stability Internal Energy as in an organism as well as in cells of an organism (Figures 2 and 3). Besides interactions between 
Citation: Ponizovskiy MR (2016) Role of Krebs Cycle in the Mechanism of Stability Internal Medium and Internal Energy in an Organism in Norm and in Mechanisms of Cancer Pathology. Mod Chem Appl 4: 191. doi: 10.4172/2329-6798.1000191

stable Krebs tricarboxylic acid cycle and advancing anabolic processes induce different charges on Internal and External Membranes of cellular capacitors, nuclear capacitors, mitochondrial capacitors and the other organelles' capacitors that contributes to maintenance stability Internal Energy of all cells via operations relative resonance waives between them $[4,12]$. Thus, TCA cycle are the joint mechanism which exerts as the mechanisms of biochemical maintenance stability Internal Energy and Internal Medium of an organism $[9,10]$ as well as the mechanism of biophysical maintenance stability Internal Energy and Internal Medium of an organism [4,12] (Figures 2 and 3).

\section{The role of Krebs tricarboxylic acids cycle in cancer metabolism}

Cancer metabolism is the result of oncogenes operation as the etiologic factors [14-17]. Just there were described following oncogenes manifestations: The operations kinase corresponded to influences of genes on mutation processes [18] Rb1 is phosphorylated by cyclin-dependent kinases (CDKs) and plays important role in DNA replication and in cells division in G2/M cellular phases, and also $\mathrm{Rb}_{1}$ is subjected to mutation in some tumors [18]. It occurs the suppression of p53 expression by $\mathrm{RNA}_{1}$ in some tumors [18]. Intruding into cellular genome of v-oncogene, the cells were subjected to accept of accelerated cellular rhythm of this v-oncogene into cellular Genome exerting huge anabolic endergonic processes in cancer tissue $1+2000 \mathrm{n} \mathrm{H}^{+} /$ that leads to shift balance catabolic exergonic processes and anabolic endergonic processes into excessive anabolic endergonic processes of cancer metabolism, as compared with normal balance catabolic exergonic processes and anabolic endergonic processes in able-bodied tissues/ $+2 \mathrm{n} \mathrm{H}^{+} /[2,3]$ (Figure 4). The excessive anabolic endergonic processes in cancer metabolism take up huge quantity energy and Acetyl-CoA that cause overload of "nodal point of bifurcation anabolic and catabolic processes" [NPBac] remaining lack of energy and Acetyl-CoA for catabolic oxidative processes promoting cancer cells' survival via showing Apoptosis Resistance. Just lack Acetyl-CoA causes the partial suppression oxidative phosphorylation of catabolic exergonic processes, i.e., Krebs citric acids cycle, in cancer metabolism [3]. The increase of lactic acids production in cancer metabolism is the necessary endergonic mechanism accumulation energy for huge anabolic processes in condition glycolysis metabolism and enormous consumption of energy in cancer metabolism. Just partial suppression of Krebs tricarboxylic acids cycle occurs in Oxaloacetate link of circular metabolic pathway between an organism and mitochondria that separates citric acids cycle of an organism from citric acids cycle of cancer cells, i.e., making autonomic mechanism of cancer cells development from an organism (Figure 5). The partial suppressed Krebs tricarboxylic acids cycle produces considerably less quantity of Hydrogen ions than in norm, that leads to remained considerably more free oxygen causing great quantity of Superoxide $\left(\mathrm{O}_{2}^{*}\right)$, considerably more than in norm, via adding electron: a) $\mathrm{O}_{2}+\mathrm{e}^{-} \rightarrow \mathrm{O}_{2}{ }^{*}[5,6]$. The great quantity of dissolved Superoxide is transported by electron transport system (ETS) across cellular membranes and mitochondrial membranes binding with cytochrome $\mathrm{c}$ that transforms iron of cytochrome $\mathrm{c}$ from $\mathrm{Fe}^{2+}$ into $\mathrm{Fe}^{3+}$ and form oxidized cytochrome $\mathrm{c}$. Then the oxidized cytochrome $\mathrm{c}$ adds electron and release free Cytochrome $\mathrm{C}$ with free Oxygen. Oxygen reacts with Hydrogen ion from Krebs cycle producing Water, i.e., elimination of free oxygen (Figures 2 and 3 ). $+\mathrm{O}_{2}$

b) cytc- $-\mathrm{Fe}^{2+}+\mathrm{O}_{2}{ }^{*} \rightarrow\left[\right.$ cytc- $\left.\mathrm{Fe}^{3+} 2 \mathrm{O}^{-}\right]$c) $\left[\right.$cytc- $\left.\mathrm{Fe}^{3+} 2 \mathrm{O}^{-}\right]+\mathrm{e}^{-} \rightarrow$ cytc- $-\mathrm{Fe}^{2+}$

d) cytc- $\mathrm{Fe}^{3+}+\mathrm{O}_{2}{ }^{*-} \rightarrow$ cytc- $\mathrm{Fe}^{2+}+\mathrm{O}_{2}$ e) $4 \mathrm{H}^{+}+\mathrm{O}_{2}=2 \mathrm{H}_{2} \mathrm{O}$

However, the quantities of consumed oxygen in the capillaries of

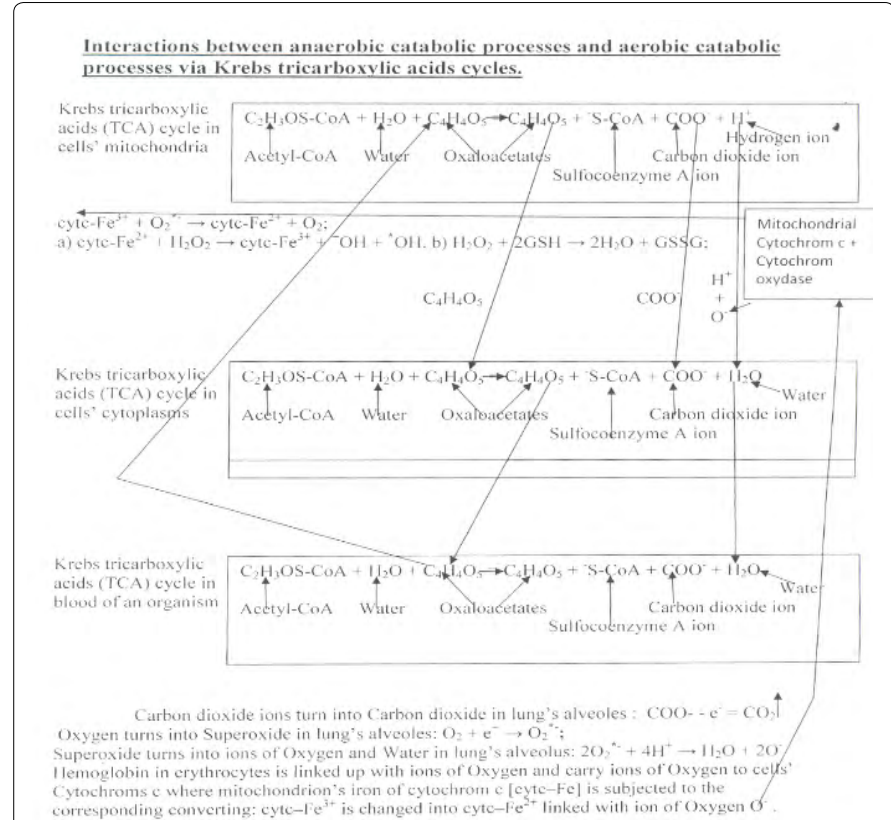

a) Oxaloacetates join three Krebs tricarboxilic citric (TCA) cycles [mitochondrialTCA, cytoplasmic TCA and an organism's extracellular TCA] making circular pathways between these Krebs tricarboxilic citric (TCA) cycles. b) The final Products of all three Krebs tricarboxilic citric (TCA) cycles [mitochondrialTCA, cytoplasmic TCA and an organism's extracellular TCA] are Carbon dioxide ions and Hydrogen ions.

c) The final Catabolic Products of Carbon dioxide ions are transferred to lung's alveoles by Carboxyhaemoglobin in blood of an organism where Carbon dioxide ions turn into Carbon dioxide.

d) Oxygen ions turn into Superoxide which reacts with Hydrogen ions resulting in Oxygen ion and Water in lung's alveoles.

e) The final Catabolic Products of Hydrogen ions react with Oxygen ion resulting Water due to Cytochrome $\mathrm{C}$ oxidase operation in mitochondrial Cytochrome $\mathrm{C}$.

Figure 3: Interactions between anaerobic catabolic processes and aerobic catabolic processes via Krebs.

lung's alveoli are considerably more than the produced Hydrogen ion in partial suppressed Krebs cycle in cancer tissue and ever than the produced Hydrogen ion in Krebs cycle in an able-bodied tissue [6]. Therefore, there are formed surplus Superoxide $\left(\mathrm{O}_{2}^{*}\right)$ in cancer tissue, considerably more quantity than in an able-bodied tissue, due to great quantity of surplus oxygen $\left(\mathrm{O}_{2}\right)$ via adding electron in cancer tissue [6].

$$
\text { f) } \mathrm{O}_{2}+\mathrm{e}^{-} \rightarrow \mathrm{O}_{2}^{*} \text {; }
$$

Then the great quantity of surplus Superoxide $\left(\mathrm{O}_{2}^{*}\right)$ considerably more than in normal tissue, is transported by electron transport system (ETS) into mitochondria in cancer tissue. Further the great quantity of surplus Superoxide $\left[\mathrm{O}_{2}^{*}\right]$ reduces Ferric iron $\left[\mathrm{Fe}^{3+}\right]$ into Ferrous iron $\left[\mathrm{Fe}^{2+}\right]$ realising also oxygen:

g) $\mathrm{O}_{2}{ }^{*}+$ cytc- $\mathrm{Fe}^{3+} \rightarrow$ cytc- $\mathrm{Fe}^{2+}+\mathrm{O}_{2}$. Simultaneously surplus Reactive Oxygen Species (ROS) is generated by NOX (NADPH oxidase) and Duoxs due to activity mitochondrial aerobic catabolic processes forming of this surplus quantity of mitochondrial superoxide $\left[\mathrm{O}_{2}^{*}\right]$.

$\mathrm{NAD}^{+}$and $\mathrm{FAD}$ are transformed in processes of surplus Superoxide $\left[\mathrm{O}_{2}^{*}\right]$ formation in cancer tissue metabolism in more intensity than in normal tissue metabolism: $\mathrm{NAD}^{+}$is transformed into reduced molecule NADH due to NADPH dehydrogenase operation, and FAD is transformed into reduced molecule $\mathrm{FADH}_{2}$. Then $\mathrm{NADH}$ is back oxidized into $\mathrm{NAD}^{+}$by $\mathrm{NADH}$ oxidase operation at Complex I, and 


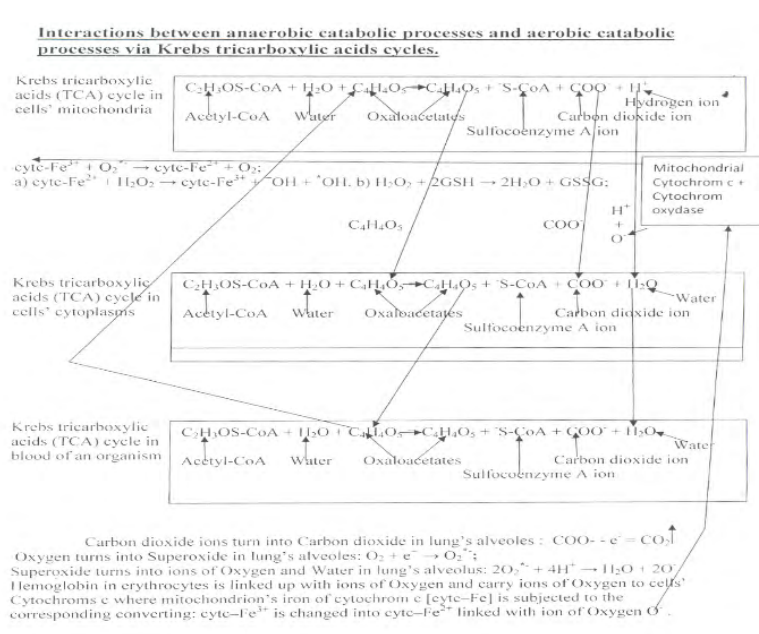

a) Nodal point of bifurcation anabolic and catabolic processes

b) Huge anabolic processes with huge consumption of energy and AcetylCoA for anabolic processes leading to overloading "Nodal point of bifurcation anabolic and catabolic processes" [NPBac] in cancer tissue.

c) Partial suppression catabolic processes due to overloading "Nodal point of bifurcation anabolic and catabolic processes" [NPBac] causing by excessive anabolic processes in cancer tissue.

d) Moderate metabolic processes displaying balance anabolic and catabolic processes in able-bodied tissue.

e) Alternative excretion of high-molecular substances within the structure rejected cells and the violation of excretion substances via oxidative processes due to suppression of catabolic oxidative processes in cancer tissue.

f) Accumulation of energy into lactic acid for anabolic processes.

g) Normal excretion substances via catabolic oxidative processes in ablebodied tissue.

Figure 4: The metabolism of a malignant tumour tissue and of a normal tissue.

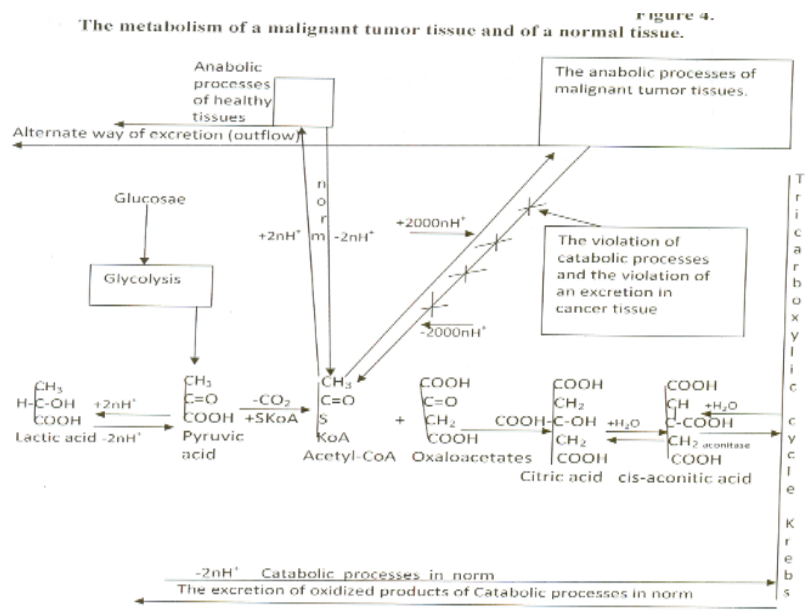

a) Oxaloacetates join three Krebs tricarboxilic citric (TCA) cycles [mitochondrialTCA, cytoplasmic TCA and an organism's extracellular TCA] making circular pathways between these Krebs tricarboxilic citric (TCA) cycles. b) Partial suppression catabolic processes due to overloading "Nodal point of bifurcation anabolic and catabolic processes" [NPBac] causing by excessive anabolic processes in cancer tissue.

c) Partial suppression catabolic processes occur in joint partial blockade of the Oxaloacetate link which joins an organism's extracellular Krebs tricarboxilic citric (TCA) cycles, connected with aerobic oxidative processes of lung's alveolus and Haemoglobin, with mitochondrial Krebs tricarboxilic citric (TCA) cycles and cytochrome c.

Figure 5: Partial Inhibition link between anaerobic catabolic processes and aerobic catabolic processes via Krebs tricarboxylic acids cycles in cancer metabolism. pair of electrons from NADH is released passing via series of electron transport carriers of electron transport system (ETS) to coenzyme Q into Complex II and further through Complex III (cytochrome bc complex) then Complex IV (cytochrome c oxidase) to Complex V (ATP synthase) into the intermembrane space $[5,6]$. The great quantity of Reactive Oxygen Species (ROS) is generated in cancer tissue by NOX (NADPH oxidase) and Duoxs due to activity mitochondrial aerobic catabolic processes forming of this great quantity of surplus quantity of mitochondrial superoxide $\left[\mathrm{O}_{2}^{*}\right]$. Also the partial surplus Superoxide anion $\left[\mathrm{O}_{2}^{*}\right]$ is accumulated into forming Reactive Oxygen Species [ROS]. However the great quantity of Superoxide anion $\left[\mathrm{O}_{2}{ }^{*}\right]$ is subjected to dismutation by manganese superoxide dismutase (MnSOD) and copper, zinc superoxide dismutase ( $\mathrm{Cu}, \mathrm{ZnSOD})$ converting into great quantity of hydrogen peroxide in cancer tissue:

h) $2 \mathrm{O}_{2}^{*-}+2 \mathrm{H}^{+}=\mathrm{H}_{2} \mathrm{O}_{2}+\mathrm{O}_{2}$

Subsequently it is happened Haber -Weiss reaction of iron catalysed by superoxide transformations which is passed into Fenton reaction which is applied to mitochondria producing free radicals $\left[{ }^{*} \mathrm{OH}\right]$ in such mode $[5,6,19-27]$

$$
\begin{aligned}
& \text { i) } \mathrm{Fe}^{3+}+\mathrm{O}_{2}{ }^{*} \rightarrow \mathrm{Fe}^{2+}+\mathrm{O}_{2} \\
& \mathrm{Fe}^{2+}+\mathrm{H}_{2} \mathrm{O}_{2} \rightarrow \mathrm{Fe}^{3+}+{ }^{-} \mathrm{OH}+{ }^{*} \mathrm{OH} \\
& \mathrm{O}_{2}{ }^{*}+\mathrm{H}_{2} \mathrm{O}_{2} \rightarrow-\mathrm{OH}+{ }^{*} \mathrm{OH}+\mathrm{O}_{2}+\mathrm{Fe}^{3+}
\end{aligned}
$$

The partial of abundance hydrogen peroxide $\left[\mathrm{H}_{2} \mathrm{O}_{2}\right]$ from ROS is detoxified by mitochondrial glutathione peroxide (GPX) and phospholipid hydroperoxide glutathione peroxide (PHGPX) in G1/S phases of cellular cycle: Glutathione (GSH) is transformed into oxidized glutathione (GSSG) in the reaction of reducing $\mathrm{H}_{2} \mathrm{O}_{2}$ into $\mathrm{H}_{2} \mathrm{O}$ which is stimulated by glutathione peroxide [5,6,28-32]. Furthermore, mitochondrial isoforms of peroxiredoxins such as peroxiredoxin-III and $\mathrm{V}$ utilize some molecules of cysteine to reduce $\mathrm{H}_{2} \mathrm{O}_{2}$ into $\mathrm{H}_{2} \mathrm{O}$ and return glutathione peroxide to its reduced state [5,6,33-35]. Thus, there are the summarized reactions of respiratory oxidative processes with generating superoxide $\left[\mathrm{O}_{2}^{*}\right]$, $\mathrm{ROS}$ and hydrogen peroxide $\left[\mathrm{H}_{2} \mathrm{O}_{2}\right][5,6]$.

The majority of abundance complex $\mathrm{ROS} / \mathrm{H}_{2} \mathrm{O}_{2} /$ free radicals operates in $G_{2}$ phase cellular cycle, inducing process replication via realizing of 2 nDNA $[6,13]$.

$$
\begin{aligned}
& \text { 1) }{ }^{*} \mathrm{OH}+\mathrm{H}_{2}-\mathrm{nDNA}-\mathrm{DNA}-->\mathrm{H}_{2} \mathrm{O}+\mathrm{H}^{\bullet}-\mathrm{nDNA}-\mathrm{DNA} \\
& \mathrm{O}^{*}+2 \mathrm{H}_{2} \mathrm{O}-->2 \mathrm{H}^{\bullet}+2 \mathrm{OH}^{-} \\
& 2 \mathrm{H}^{\bullet}-\mathrm{nDNA}-\mathrm{DNA}+2 \mathrm{H}^{\cdot}-->2 \mathrm{nDNA}-\mathrm{H}^{\bullet}+2 \mathrm{nDNA}-\mathrm{H}^{\bullet}
\end{aligned}
$$

$2 \mathrm{nDNA}-\mathrm{H}^{\bullet}+2^{*} \mathrm{OH}-->2 \mathrm{nDNA}+\mathrm{H}_{2} \mathrm{O}$

Thus, $\mathrm{ROS} / \mathrm{H}_{2} \mathrm{O}_{2} /$ Free radicals exert excessive processes of DNA replication which promote the full neutralization of $\mathrm{ROS} / \mathrm{H}_{2} \mathrm{O}_{2} /$ Free radicals, eliminating their ruining properties in $G_{2}$ phase oncologic cellular cycle. Also the great acceleration of cellular cycle, induced by oncogene, leads to unnoticeable $\mathrm{G}_{\mathrm{o}}$ phase in oncologic cellular cycle. Division cell in $\mathrm{M}$ phase oncologic cellular cycle leads to forming new cells in G1/S cellular cycle due to acceleration cellular cycle and unnoticeable $G_{o}$ phase cellular cycle. The great acceleration of cellular cycle, induced by oncogene, with combination of abundance ROS and excessive processes of DNA replication causing neutralization ROS/ $\mathrm{H}_{2} \mathrm{O}_{2}$ /Free radicals eliminates these incompatible resisted situations in metabolism of cancer cells, induced by mechanism of abundance ROS function: On the one hand, large amount of ROS production with hydrogen peroxide in mitochondria of cancer cells which would lead to apoptotic damage of cancer cells, and, on the other hand, cancer 
metabolism is characterized by Apoptosis Resistance [3,6,26]. Just it is the mechanism Apoptosis Resistance in oncologic cellular cycle. Oncologic cellular cycle is characterized by expression huge anabolic processes in cellular oncogenesis. Hence the excessive shift of the balance anabolic and catabolic processes into abundance anabolic processes with accelerating cellular cycle in cancer tissue advances cellular cycle in cellular oncogenesis via $G_{1} / S, G_{2}$ and $M / G_{1} / S$ phases which create chemical potentials unrelated to chemical potentials as an organism as well as between new formed cells that is driver mechanism of proliferative processes leading to formation Warburg effect with excessive proliferative processes, irrepressible cancer growth, unhealed cancer wounds, mechanisms of metastasis and Apoptosis Resistance [36]. Thus, it is formed Warburg effect mechanism of "aerobic glycolysis" in cancer metabolism, versus Pasteur effect "incompatibility aerobic oxidation with glycolysis" in able-bodied tissue [3,19-26] (Figure 4 and 5). Thus, cellular oncogenesis exhibits abundance ROS which is also driving mechanism of excessive processes of DNA replication in G2 phase cellular cycle leading to excessive cancer cells proliferative processes $[3,5,6]$.

Highlight of cancer genesis: As outcome of oncogenes operation, the huge anabolic processes cause huge consumption of energy and Acetyl-CoA and partial suppress the catabolic processes in cancer tissue. Lactic acids accumulate energy for anabolic processes in condition glycolysis metabolism remaining the part of the energy oxidative phosphorylation in Krebs tricarboxylic acids cycle which generate energy for maintenance stability Internal Energy of an organism and cells of an organism how temperature $36,6^{\circ} \mathrm{C}-37.0^{\circ} \mathrm{C}$ by which all enzymes operate etc. Also this energy is used for cancer cells survival displaying Apoptosis Resistance. The partial suppressed TCA produces considerably less quantity of Hydrogen ions than in norm, that leads to remained considerably more free oxygen causing productions great quantity of abundance complex $\mathrm{ROS} / \mathrm{H}_{2} \mathrm{O}_{2} /$ Free radicals which induce process replication via realizing of $2 \mathrm{nDNA}$ exerting excessive irrepressible proliferative processes. Thus, it forms Warburg effect mechanism of "aerobic glycolysis" which creates Apoptosis Resistance of cancer cells, metastasis, irrepressible cells growth, unhealed cancer ulcer and so on.

\section{Exertion expression Krebs tricarboxylic citric acids cycle in cancer metabolism for prevention supplementary metastasis in processes of up-to-date chemotherapy}

The mechanisms of prevention supplementary metastasis in processes of up-to-date chemotherapy: There are lot of theories of cancer metastasis mechanism [3,36-38]. Some theories explain mechanism of cancer metastasis because of the low expression of $\mathrm{K}^{+}$ in the $\mathrm{Kv}$ channel of malignant tumors [36-38]. We have chosen the described mechanism of metastasis based on explanation mechanism of Warburg effect by Ponisovskiy MR [3] and also the role of mitochondrial frataxin protein in mechanism of cancer metastasis $[3,39]$. "The huge anabolic processes cause the blockade of excretion (outflow) the synthesized high-molecular substances from cancer tissue by the pathway of oxidative metabolism because of overload "NPBac" and "lack of Acetyl-CoA for oxidative processes" in cancer tissues (Figure 4). Therefore, the alternative pathway of high-molecular substance excretion takes place within separate cells. The viable separate cells transit from the malignant tumor tissue into the Internal Medium of the organism (blood or lymph) and, being diffused by lymph or blood, get to a healthy place of extracellular matrix without overloaded "NPBac" and "lack of Acetyl-CoA" and form metastases. Just it is happened the suppression of mitochondrial frataxin due to overloaded "NPBac" and "lack of Acetyl-CoA" promoting suppression catabolic oxidative processes [3-39]. Also the overloaded "NPBac" and "lack Acetyl CoA", which is the carrier of $\mathrm{K}^{+}$ions in $\mathrm{Kv}$ channel, contribute to the low expression of $\mathrm{K}^{+}$in the $\mathrm{K}_{\mathrm{v}}$ channel of malignant tumors in condition of cancer metastasis [36-38]. Thus, the suppression catabolic processes due to overloaded "NPBac" and "lack of Acetyl-CoA touches on TCA cycle via inhibition link of transferring Oxaloacetates from an organism to cancer cells violating link between mitochondrial Citric Acids cycle and mitochondrial system of cytochrome due to decreased production of quantity Hydrogen ions in Krebs tricarboxilic acids cycle (Figure 5). The study of cancer metastasis mechanism contributes to use of citric acids from citric juice, in which there is preserved the enzymes for Citric Acids cycle, that exerts as expression Krebs tricarboxylic citric acids cycle in cancer cells as well as increases Acetyl-CoA eliminating overloaded "NPBac" and causing prevention additional metastasis in processes of up-to-date chemotherapy. Really excessive quantity of citric acids with appropriate enzymes increases quantity Acetyl-CoA due to maintenance stable index of Equilibrium Constant reaction in Krebs tricarboxilic acids cycle [1] Acetyl-CoA + Oxaloacetate $\leftrightarrow$ Citric acid. This reaction in Krebs tricarboxylic acids cycle moves right saving stable Equilibrium Constant of reaction: Acetyl-CoA + Oxaloacetate $\rightarrow$ Citric acid. However, this reaction moves left in condition of excessive increase of quantity citric acid saving stable Equilibrium Constant via increase quantity of Acetyl-CoA too: Acetyl-CoA + Oxaloacetate $\leftarrow$ Citric acid. Increase quantity of Acetyl-CoA eliminates overloaded "NPBac" that cause prevention additional metastasis in processes of up-to-date chemotherapy. Besides excessive increased quantity citric acid exerts Citric Acids cycle causing expression of catabolic exergonic processes that induce also mitochondrial frataxin protein operation in cytochrome $\mathrm{c}$ catabolic aerobic processes inhibiting cancer metabolism and preventing cancer metastasis in processes of up-todate chemotherapy.

Some clinical observation of using offered method prevention cancer metastasis: At 2010 year the man Pol. was examined and was found out a polyp in the large intestine. The repeated investigation was made at December 10, 2014 and was found cancer of large intestine. There was made the operation in which proceeding it was found the multiple metastasis in visceral peritoneum. The sick Pol. has refused himself from the offered alternative therapy of "Prolonged medical starvation during 45 days with small dosage cytotoxic remedy" [4043]. He has chosen up-to-date method of chemotherapy. At December 2014, the sick Pol. has begun to receive chemotherapy treatment with Fluorouracil and Erbitux immunotherapy. Taking into account the above described mechanisms of the role citric acids operation in Citric acids cycle, I have recommended to use citric juice from the squeezed two citrons during day, i.e., over the entire circadian period, which should be diluted in 1 litre water for prevention intestine irritation from great concentration of citric acids. This method must be used simultaneously with chemotherapy, as the additional method for prevention new metastasis. The patient Pol. has drunk the citric juice prepared in such mode during two months. Then patient Pol. has drunk the citric juice from the squeezed one citron daily which was diluted in 1 litre water. The weekly examinations show that there were not found new metastasis by the patient Pol. during the period from December 2014 till September 2016. The state of the patient Pol. is satisfactory.

\section{Conclusions}

The common pathway of both Glycolysis and Krebs tricarboxylic acid cycle gives possibility to estimate as combination related catabolic exergonic anaerobic processes and catabolic exergonic aerobic processes as well as their interactions with opposed them anabolic endergonic processes. The common pathway of both Glycolysis and 
Citation: Ponizovskiy MR (2016) Role of Krebs Cycle in the Mechanism of Stability Internal Medium and Internal Energy in an Organism in Norm and in Mechanisms of Cancer Pathology. Mod Chem Appl 4: 191. doi: 10.4172/2329-6798.1000191

Page 7 of 8

Krebs tricarboxylic acid cycle is the basic link of balance catabolic exergonic processes and anabolic endergonic processes which is also the basic link of mechanism maintenance stability Internal Energy of an organism and cells of an organism according first law of thermodynamics. Acetyl-CoA is the joining link in "nodal point of bifurcation catabolic and anabolic processes [NPBac]" between anabolic endergonic processes and catabolic exergonic anaerobic processes exhibiting oxidative phosphorylation processes of Glycolysis and Krebs tricarboxylic cycle. Oxaloacetates are the joining links between Krebs tricarboxylic cycles of an organism's cells and Krebs tricarboxylic cycles of an organism making the joint between catabolic exergonic anaerobic processes and catabolic exergonic aerobic exergonic oxidative processes. Citric acid is the primary link of driving mechanism Krebs tricarboxilic citric cycle which governs direction reaction among Glycolysis and Krebs tricarboxilic citric cycle as the product of reaction between Acetyl-CoA and Oxaloacetate. It was described mechanism maintenance stability Internal Energy of an organism in processes of respiratory in norm. The accelerated cellular rhythm of the v-oncogenes intrusted into cellular Genome exerts accelerated proliferative processes with huge anabolic endergonic processes of cancer oncogenesis leading to shift balance catabolic exergonic processes and anabolic endergonic processes into excessive anabolic endergonic processes of cancer metabolism. Consuming huge quantity both energy and Acetyl-CoA for excessive anabolic endergonic processes, it occurs overload of "nodal point of bifurcation anabolic and catabolic processes" [NPBac] in point of Acetyl-CoA that leads to remaining lack of energy and Acetyl-CoA for catabolic oxidative processes and causes the partial suppression oxidative phosphorylation of catabolic exergonic processes in cancer metabolism forming mechanism of Warburg effect. Lactic acids accumulate energy for excessive anabolic processes in condition glycolysis metabolism remaining the part of the energy oxidative phosphorylation in Krebs tricarboxylic acids cycle for cancer cells' survival exhibiting Apoptosis Resistance of cancer metabolism. The partial suppression of Krebs tricarboxylic acids cycle occurs in Oxaloacetates link of its circular pathway between an organism and mitochondria that separates Citric Acids Cycle of an organism from Citric Acids Cycle of cancer cells, making autonomic mechanism of cancer cells development. The partial suppressed Krebs tricarboxylic acids cycle produces considerably less quantity of Hydrogen ions than in norm, that leads to remained considerably more free oxygen causing productions great quantity of Superoxide $\left(\mathrm{O}_{2}{ }^{*}\right)$, considerably more than in norm. Superoxide $\left(\mathrm{O}_{2}^{*}\right)$ binds with cytochrome $\mathrm{c}$ that transforms iron of cytochrome $\mathrm{c}$ from $\mathrm{Fe}^{2+}$ into $\mathrm{Fe}^{3+}$ and form oxidized cytochrome c. The oxidized cytochrome $\mathrm{c}$ adds electron and release free Cytochrome $\mathrm{C}$ with free Oxygen which reacts with Hydrogen ion from Krebs tricarboxylic acids cycle resulting in production Water. The quantities of consumed oxygen in the capillaries of lung's alveoli are considerably more than the produced Hydrogen ion in Krebs tricarboxilic acids (TCA) cycle that leads to form surplus Superoxide $\left(\mathrm{O}_{2}{ }^{*}\right)$ which reduces Ferric iron $\left[\mathrm{Fe}^{3+}\right]$ into Ferrous iron $\left[\mathrm{Fe}^{2+}\right]$ with production oxygen, and this great quantity surplus Superoxide $\left(\mathrm{O}_{2}^{*}\right)$ are subjected to dismutation into great quantity of hydrogen peroxide in cancer tissue. The partial surplus Superoxide anion $\left[\mathrm{O}_{2}^{*}\right]$ is accumulated into forming Reactive Oxygen Species [ROS]. Haber-Weiss reaction of iron catalysed by superoxide transformations which is passed into Fenton reaction which is applied to mitochondria producing free radicals $\left[{ }^{*} \mathrm{OH}\right]$. The abundance complex ROS $/ \mathrm{H}_{2} \mathrm{O}_{2}$ /free radicals operates in $\mathrm{G}_{2}$ phase cellular cycle of cancer cells and induce process accelerating replication via realizing of 2nDNA leading to irrepressible proliferation of cancer cells. The use of citric acids in citric juice, in which it was preserved the enzymes for Citric Acids cycle, exerts as expression Krebs tricarboxylic citric acids cycle in cancer cells as well as increases Acetyl-CoA eliminating overloaded "NPBac" and causing prevention additional metastasis in processes of up-to-date chemotherapy. There was described the some preliminary clinical positive results of use the offered method of prevention additional metastasis with chemotherapy by cancer patient.

\section{Acknowledgments}

This article is dedicated to the memory of my daughter TM Ponizovskiy.

\section{References}

1. Ponizovskiy MR (2014) The mechanisms operation of thermodynamic system of a human organism. European Journal of Biophysics 2: 29-37.

2. Ponizovskiy MR (2013) Biophysical and biochemical models of cellular development mechanisms via cellular cycle as in normal tissue and as well as in cancer tissue and in inflammatory processes. Critical Reviews in Eukaryotic Gene Expression 23: 171-193.

3. Ponizovskiy MR (2010) Cancer metabolism and the Warburg effect as anabolic process outcomes of oncogene operation. Critical Reviews in Eukaryotic Gene Expression 20: 325-339.

4. Ponizovskiy MR (2015) Biophysical and biochemical mechanisms of interactions cytoplasm processes with nucleus processes and mitochondria processes in norm and pathology. Journal of Molecular and Genetic Medicine 9: 1-13.

5. Furda AM (2011) The role of MT DNA damage in mitochondrial dysfunction. University of Pittsburg, pp: 145

6. Ponizovskiy MR (2013) Biophysical and biochemical transmutation of mitochondrial function in cancer genesis. Biochemistry and Analytical Biochemistry 2: 1-9.

7. Selak AM, Sean MA, Elaine D, Kenzie M (2005) Succinate link TCA cycle disfunction to oncogenesis by inhibition HIF- $\alpha$ prolil hydroxylase. Cancer cell 7: 77-85.

8. Wellen KE, Hatzivassiliou G, Sachdeva UM, Bui TV, Cross JR, et al. (2009) ATP-citrate lyase links cellular metabolism to histone acetylation. Science 324 1076-1080.

9. Ponizovskiy MR (2013) The Central Regulation of all Biophysical and Biochemical Processes as the Mechanism of Maintenance Stability of Internal Energy and Internal Medium both in a Human Organism and in cells of an Organism. Modern Chemistry \& Applications 1: 1-2

10. Ponizovskiy MR (2013) The mechanisms maintenance stability Internal Energy and Internal Medium an organism in norm and in quasi-stationary pathologic states. Biochemistry \& Physiology 2: 1-11.

11. Connie CW, Hsia MD (1998) Respiratory function of haemoglobin. The new England journal of Medicine 338: 239-248.

12. Ponisovskiy MR (2011) Driving mechanisms of passive and active transport across cellular membranes as the mechanisms of cell metabolism and development as well as the mechanisms of cellular distance reaction on hormonal expression and the immune response. Critical Reviews in Eukaryotic Gene Expression 21: 267-290.

13. Emanuel NM (1977) Kinetics experimental tumorous processes. Moscow Science, p: 419

14. Altenberg B, Greulich KO (2004) Genes of Glycolysis are ubiquitously overexpressed in 24 cancer classes. Genomics 6: 1014-1020.

15. Donna DM, Paolo B, Luigi CB, Vincenzo C (2005) Mitochondria as Functional Targets of Proteins coded by Human Tumour Viruses in Mitochondria as Central Regulators of Energy Concervation. Signal Transduction and 94 Academic Press, pp: 87-94.

16. Vaux DL, Cory S, Adams JM (1988) Bcl-2 gene promotes haemopoietic cell survival and cooperates with c-myc to immortalize pre-B cells. Nature 335: 440-442.

17. Cheng JQ, Altomare DA, Klein MA, (1997) Transforming activity and mitosisrelated expression of the AKT2 oncogene: evidence suggesting a link between cell cycle regulation and oncogenesis. Oncogene 14: 2793-2801.

18. Brenner C, David D (2004) Oncogenomics: Molecular Approaches to Cancer, p: 382

19. Weinhouse S (1957) Oxidative metabolism in a tumoral tissue. In: Advances in Cancer Research. Shabad LM (ed.), Moscow: Foreign Literature. Vol. III, pp: 185-218. 
Citation: Ponizovskiy MR (2016) Role of Krebs Cycle in the Mechanism of Stability Internal Medium and Internal Energy in an Organism in Norm and in Mechanisms of Cancer Pathology. Mod Chem Appl 4: 191. doi: 10.4172/2329-6798.1000191

20. Van PR, Page LGA (1949) Metabolism of oxaloacetate in glycolyzing tumour homogenates. J Biol Chem 177: 237-245.

21. Kim JW, Dang CV (2005) Multifaceted roles of glycolytic enzymes. Trends Biochem Sci 30: 142-150.

22. Kim JW, Dang CV (2006) Cancer's Molecular Sweet Tooth and the Warburg effect. Cancer Research 66: 8927-8930.

23. Dang CV (2007) The interplay between MYC and HIF in the Warburg effect. Ernst Schering Found Symp Proc 4: 35-53.

24. Garber K (2004) Energy Boost: The Warburg Effect Returns in a New Theory of Cancer. Journal of the National Cancer Institute 96: 1805-1806.

25. Garber K (2006) Energy Deregulation: Licensing Tumour's to Grow. Science 312: $1158-1159$

26. Elstrom RL Bauer DE, Buzzai M, Karnauskas R, Harris MH, et al. (2004) Stimulates Aerobic Glycolysis in Cancer Cells. Cancer Res 64: 3892-3899.

27. Tedesco AC, Martínez L, González S (1997) Photochemistry and photobiology of actinic erythema: defensive and reparative cutaneous mechanisms. Braz J Med Biol Res 30: 561-575.

28. Frohe $L$ (1982) Free radicals in biology. In: Pryor WA (ed.), Academic Press, New York, pp: 223-275.

29. Rhee SG (2006) Cell signaling $\mathrm{H}_{2} \mathrm{O}_{2}$ a necessary evil for cell signaling. Science 312: 1882-1883.

30. Lambert AJ, Brand MD (2009) Reactive oxygen species production by mitochondria Methods. Mol Biol 554: 165-181.

31. Schafer FQ, Buettner GR (2001) Redox environment of the cell as viewed through the redox state of the glutathione disulfide/glutathione couple. Free Radic Biol Med 30: 1191-1212.

32. Lara G, Marcello P, Milena N (2010) Interfering with ROS metabolism in Cancer Cells. The Potential Role of Quercetin Cancers 2: 1288-1311.
33. Seo MS, Kang SW, Kim K (2000) Identification of a new type of mammalian peroxiredoxin that forms an intramolecular disulfide as a reaction intermediate. J Biol Chem 275: 20346-20354.

34. Banmeyer I, Marchand C, Clippe A, Knoops B (2005) Human mitochondrial peroxiredoxin 5 protein from mitochondrial DNA damages induced by hydrogen peroxide. FEBS Lett 579: 2327-2333.

35. Wood ZA, Schroder E, Robin HJ, Poole LB (2003) Structure mechanism and regulation of peroxiredoxins. Trends Biochem Sci 28: 32-40.

36. Kent HW, Nigel CPS, Alsarrai J (2008) Mechanisms of metastasis. Breast Cancer Research 10: S2.

37. Sebastien B, Stephen AL, Joan AT, Alois H, Christian B, et al. (2007) A Mitochondria- $\mathrm{K}^{+}$Channel Axis is suppressed in Cancer and its Normalization promotes Apoptosis and inhibits Cancer Growth. Cancer Cell 11: 37-51.

38. Wang Z (2004) Roles of $\mathrm{K}^{+}$channels in regulating tumour cell proliferation and apoptosis. Pflugers Arch 448: 274-286.

39. Tim SJ, Rene T, Voigt A (2006) Induction of Oxidative Metabolism by Mitochondrial Frataxin Inhibits Cancer Growth. The Journal of Biological Chemistry 281: 977-981.

40. Ponisovskiy MR (2011) Warburg effect mechanism as the target for theoretical substantiation of a new potential cancer treatment. Critical Reviews in Eukaryotic Gene Expression 21: 13-28.

41. Ponizovskiy MR (2012) The detailed description mechanisms of the herbs extracts operations in the new method cancer disease treatment via rearrangement of metabolism from pathologic development into normal development. Journal of Clinical Trials 2: 1-10.

42. Ponizovskiy MR (2014) Cancer therapy via targeting Warburg effect leads to cancer metabolism depression that promotes efficient treatment with small dosage cytotoxic drugs. American Journal of Cancer Science 3: 30-53.

43. Ponizovskiy MR (2015) Cancer therapy leading to state of cancer metabolism depression for efficient operation of small dosage cytotoxic drugs. Journal of Cancer Research \& Therapy 3: 38-55. 